\title{
Regionalismo y catalanismo en la Universidad de Valencia (1975-1977)
}

\author{
Regionalism and Catalanism at the University \\ of Valencia (1975-1977)
}

\author{
Ramon Aznar i Garcia \\ Universidad Internacional de Valencia \\ ORCID ID: 0000-0001-6471-1838
}

Recibido: $\quad 30 / 08 / 2021$

Aceptado: $\quad 25 / 10 / 2021$

DOI: https://doi.org/10.20318/cian.2021.6444

\begin{abstract}
Resumen: El artículo analiza las diferentes perspectivas que, sobre la cuestión regional/nacional valenciana, adoptaron una serie de profesores universitarios entre 1975 y 1977. La mayoría de estos académicos representaron a sus organizaciones políticas en la Taula de Forces Polítiques i Sindicals del País Valencià, organismo unitario de la oposición democrática constituido en la primavera de 1976. Algunos, además, obtuvieron el acta de diputado con ocasión de las elecciones generales de junio de 1977, que acabaron siendo constituyentes. Interesa identificar los puntos de vista de estos intelectuales, pues sus consideraciones influyeron -en un sentido u otro- en la que fue una de las cuestiones más controvertidas de la transición democrática. En el caso valenciano se estaba gestando,
\end{abstract}

\begin{abstract}
The article analyzes the different perspectives that a series of university professors adopted between 1975 and 1977 on the Valencian regional / national issue. Most of these academics represented their political organizations in the Taula de Forces Polítiques i Sindicals del País Valencià, an united organization of the democratic opposition constituted in the spring of 1976. Some, in addition, obtained the act of deputy on the occasion of the general elections of June 1977, which ended up being constituents. It is interesting to identify the points of view of these intellectuals, as their considerations influenced -in one sense or another- what was one of the most controversial issues of the democratic transition. In the Valencian case, a vivid identity conflict was also developing and
\end{abstract}

"raznar@universidadviu.com 
además, un vivo conflicto identitario que iba a condicionar el acceso a la preautonomía y - años después- a la autonomía misma.

Palabras clave: Universidad de Valencia; Transición democrática; regionalismo; nacionalismo; estatuto de autonomía; País Valenciano; Países Catalanes. would determine the access to pre-autonomy and - years later - to autonomy itself.

Key words: University of Valencia; Democratic transition; regionalism; nationalism; statute of autonomy, Valencian Country, Catalan Countries.

\section{Introducción}

Este artículo forma parte de una investigación que tiene por objeto el estudio del acceso a la autonomía valenciana, y abarca el periodo comprendido entre 1975 y 1977. Por entonces, lo que se ha dado en llamar la Transición no era aún un concepto asentado y no se disponía aún del canon hermenéutico que, después, la historiografía ha ido construyendo. Durante el bienio analizado, el concepto reforma era asumido, tanto por quienes quisieron introducir cambios en el régimen, como por quienes impulsaban un cambio de régimen. La manifestación más elocuente de ello lo constituye la promulgación de la Ley 1/1977, de 4 de enero, para la Reforma Política, que fue aprobada por los procuradores de las Cortes Españolas con el acuerdo, al menos tácito, de las principales fuerzas de la oposición democrática. Ciertamente, a lo largo de 1977 y en el marco de la aprobación de la referida norma, las principales organizaciones democráticas prescindieron de su reivindicación de formar un gobierno provisional y pasaron a poner el acento en la apertura de un proceso constituyente. Ahora bien, ello se llevó a cabo, formalmente, en los términos de un programa de reforma (la Transición) y no de ruptura. Obviamente, en el plano de los hechos, quedaba atrás un régimen dictatorial, lo que posibilita que, sobre todo en términos historiográficos, pueda hablarse de ruptura. Hay que ser consciente que aquella operación políticoinstitucional (la Transición) hizo uso de un determinado léxico, en el que el término reforma desempeñó un papel clave, en detrimento del de ruptura, por entonces menos útil al propósito de lograr una amplia adhesión social que legitimase los cambios en ciernes.

En 1977 y en la región valenciana, hubo organizaciones e intelectuales que no aceptaron los presupuestos y los efectos de la Ley de Reforma Política. Estos actores quedaron al margen de los acuerdos alcanzados entre el gobierno y los principales partidos de la oposición democrática y, formalmente, persistieron en un planteamiento rupturista, aun cuando, por supuesto, no fueron las únicas organizaciones que propugnaron, en el plano de los hechos, la superación de la dictadura. 
Las fuentes periodísticas representan una vía de acceso crucial al conocimiento del objeto de estudio. Entre 1975 y 1977, se produjo una eclosión de publicaciones que, con amplia libertad y pluralidad de criterios y de perspectivas, dieron cuenta detallada de las distintas propuestas y problemáticas. Tratándose de la transición democrática española, no resulta infrecuente que el acceso a los fondos documentales (institucionales o personales) adolezca de serias limitaciones. Se destruyó documentación comprometida. Era habitual el uso de un registro expresivo parco en palabras en cuestiones políticas. Aún hoy, la legislación veta el acceso a determinada documentación. A todo ello, podríamos añadir la complicación sobrevenida que ha supuesto la reciente pandemia y la imposibilidad, durante largos meses, de poder acceder a los fondos de archivo no digitalizados. En cualquier caso, el artículo se basa en la consulta de bibliografía crítica, prensa escrita, libros editados durante el periodo analizado y documentación de archivo, fundamentalmente del fondo Alfons Cucó de la Universidad de Valencia.

\section{La cuestión territorial en Europa y España}

En la década de los sesenta del siglo XX y en el contexto del proceso de descolonización auspiciado por la $\mathrm{ONU}$, la preocupación regionalista se situó de lleno en los principales foros políticos y académicos de Europa Occidental. El Consejo de Europa constituyó la Conferencia Europea de Poderes Locales, cuya cuarta sesión, celebrada en 1962, determinó que «una sana política de ordenación del territorio debe operarse bajo la autoridad de los poderes directamente interesados, de las autoridades regionales y locales directamente designadas por las poblaciones y responsables ante ellas» ${ }^{1}$. En Italia, los habitantes del Alto Adige habían planteado internacionalmente sus demandas autonomistas y se publicaron varias monografías sobre la cuestión regional $^{2}$. En Francia, tres decretos ministeriales abordaron la «desconcentración administrativa», las «circunscripciones de acción regional» del Estado

${ }^{1}$ Henry Cravatte, "La Conference Européenne des Pouvoirs Locaux", Annuaire Européen-European Yearbook, 10 (1962): 43-62, 56.

${ }^{2}$ Sobre las demandas suscitadas en el Alto Adige, véase $A B C, 19-10-1960$, p. 53. Asimismo, pueden consultarse Ettore Rotelli, ed., Il regionalismo italiano. Antologia del pensiero regionalista dal Risorgimento ai nostri giorni (Milano: Comune di Milano,1962); Ernesto Ragioneri, Politica e amministrazione nella storia dell'Italia unita (Bari: Laterza, 1967) y Ettore Rotelli, L'avvento della Regione in Italia. Dalla caduta del regime fascista alla Costituzione repubblicana (1943-1947) (Milano: Giuffrè, 1967). 
y el «desarrollo económico regional» ${ }^{3}$. Poco después, Robert Lafont dio a la imprenta La révolution régionaliste ${ }^{4}$.

En España, Juan Ferrando Badía - influenciado por la obra de Gaspare Ambrosini- publicó Formas de Estado desde la perspectiva del Estado regional, libro en el que definía un tipo intermedio de Estado, entre el unitario y el federal, caracterizado por una autonomía que incluía órganos legislativos, ejecutivos y jurisdiccionales ${ }^{5}$. Unos años después, la Ley Orgánica del Estado, de 10 de enero de 1967, previó la posibilidad de establecer «divisiones territoriales distintas de la Provincia». A este propósito, hubo quien contempló la posibilidad de que «el Caudillo legisle per se con valor constitucional acerca de algunas cuestiones relativamente marginales, como, por ejemplo [...] el estatuto jurídico de las regiones» ${ }^{6}$. Sin embargo, dicha eventualidad no obtuvo concreción normativa alguna; probablemente, debido a la influencia del fracaso de la reforma regional auspiciada por el general De Gaulle, y la dimisión de éste en 1969. No fue, pues, hasta la muerte del general Franco cuando el presidente Carlos Arias Navarro trasladó a los procuradores reunidos en Cortes la voluntad gubernamental de que «todas las regiones de España dispongan de una organización institucional» ${ }^{7}$.

De inmediato, se pusieron en marcha unas comisiones de estudio que habían de evaluar la viabilidad de un régimen administrativo especial para las provincias de Vizcaya y Guipúzcoa, y se negoció la creación de otra para

\footnotetext{
${ }^{3}$ Véase Décret no 64-250 du 14 mars 1964 relatif aux pouvoirs des préfets, à l'organisation des services de l'Etat dans les départements et à la déconcentration administrative; Décret $\mathrm{n}$ 64-251 du 14 mars 1964 relatif à l'organisation des services de l'Etat dans les circonscriptions d'action régionale; y Décret no 64-252 du 14 mars 1964 portant création de commissions de développement économique regional. Journal Officiel de la République Française (no 68, 20-3-1964), pp. 2.588-2.592. Disponible en https://www.legifrance.gouv.fr/jorf/id/JORFTEXT000000862744/ [Citado el 30-8-2021].

${ }^{4}$ Robert Lafont, La révolution régionaliste (Paris: Gallimard, 1967).

${ }^{5}$ Juan Ferrando Badía, Formas de Estado desde la perspectiva del Estado regional (Madrid: Instituto de Estudios Políticos, 1964).

${ }^{6}$ Rodrigo Fernández-Carvajal, La Constitución Española (Madrid: Editora Nacional, 1969), 20.

${ }^{7}$ En su discurso, el presidente Arias también aludió al carácter abierto y voluntario del proceso de regionalización en ciernes: «Precisamente porque respeta profundamente la personalidad varia de las regiones de España, el Gobierno no quiere proponer aquí unas estructuras organizativas determinadas y uniformes. Entiende que deben tener la iniciativa las propias regiones, comenzando a utilizarse las vías de las Mancomunidades recientemente incorporadas a nuestra legislación. Sólo si estas estructuras regionales surgen así, en función de necesidades concretas y con carácter voluntario, tendremos la seguridad de que el regionalismo, dentro del Estado español, será algo serio y enraizado en el pueblo». Véase $A B C$, 29-1-1976, p. 9.
} 
las cuatro provincias catalanas ${ }^{8}$. Esta preocupación regionalista de las autoridades franquistas se manifestó enseguida en los medios institucionales valencianos, y los presidentes de las diputaciones provinciales de Alicante, Castellón y Valencia acordaron la creación de una «comisión que proceda al estudio y redacción de unas bases encaminadas a poner en práctica [...] la constitución de una mancomunidad regional de Diputaciones»" También la redacción de un estatuto regional se contó entre las previsiones de los principales políticos valencianos del régimen, quienes se reunieron en la Casa Regional de Valencia, en Madrid, «como respuesta de colaboración de las demandas del gobierno» ${ }^{10}$. Todos estos movimientos se formalizaron asimismo ante las Cortes Españolas por medio de una solicitud de «autonomía económica, administrativa y cultural de la región valenciana», presentada por varios procuradores valencianos ${ }^{11}$.

${ }^{8}$ Véase Orden de 3 de diciembre de 1975, por la que se fija la composición de la Comisión para el estudio de la implantación de un régimen administrativo especial para las provincias de Vizcaya y Guipúzcoa (BOE de 10-12-1975); Orden por la que se modifica la del 3 último, que fija la composición de la Comisión para el estudio de la implantación de un régimen administrativo especial para las provincias de Vizcaya y Guipúzcoa (BOE de 23-2-1976); y Decreto 405/1976, de 20 de febrero, por el que se crea una Comisión para el estudio de un régimen especial de las cuatro provincias catalanas (BOE de 9-3-1976).

${ }^{9}$ «Con nueve acuerdos preliminares se sientan las bases para la constitución de una mancomunidad de las provincias valencianas. Trascendental encuentro entre los presidentes de las tres Diputaciones del antiguo Reino». $A B C, 29-1-1976$, p. 31. Sobre esta cuestión, véanse las sesiones del pleno de la Diputación Provincial de Valencia de 8 y 27 de febrero, 26 de marzo y 30 de abril de 1976. Archivo de la Diputación Provincial de Valencia (ADV), A. 1. 1, vol 130, fols. 136v, 157v, 172v y 200r. Las actas, digitalizadas, se pueden consultar en http://nfweb20.dival. es/mainframe.asp?Appname= id0300\&user=actaslink\&password=a\&openinthispanel=1

${ }^{10} A B C, 31-1-1976$, pp. 5 y 20.

${ }^{11}$ Boletín Oficial de las Cortes Españolas (BOCE), de 12-8-1976, pp. 36.858-36.862. Con carácter general, sobre la transición valenciana, véase Ramon Aznar i Garcia, "Los inicios de la transición democrática valenciana”, Revista Electrónica de Historia Constitucional, 21 (2020): 277-299 y "L'exclusió valenciana de la reforma política española", en Els valencians, poble d'Europa. L'horitzó federal, ed. Joan Alfred Martínez i Seguí, August Monzon i Arazo y Francisco Javier Palao Gil (Valencia: Universidad de Valencia, 2019), 91-128; Vega Rodríguez-Flores, Fer país. Comunismo valenciano y problema nacional (1970-1982) (Valencia: Alfonso el Magnánimo, 2019); Lluís Bernat Prats Mahiques, Democràcia cristiana i valencianisme. Història de la UDPV (1965-1978) (Valencia: Alfonso el Magnánimo, 2019); Vega Rodríguez-Flores, "Por un País Valenciano libre autónomo y socialista. El PSOE y la identidad valenciana (1974-1978)", Pasado y Memoria. Revista de Historia Contemporánea, 17 (2018): 103-125; Vega RodríguezFlores, coord., El 9 d'Octubre de 1977. El País Valencià quaranta anys després (Catarroja: Afers, 2017); Josep Martí Castelló, Socialistes d'un país imaginat. Una història del Partit Socialista del País Valencià (1974-1978) (Valencia: Alfonso el Magnánimo, 2017); Juan Luis Sancho Lluna, Los orígenes históricos del anticatalanismo de la transición valenciana (1976-1982). Tradición, re- 
Tras el nombramiento de Adolfo Suárez como presidente del Gobierno, en junio de 1976, tres opciones se presentaban en el tablero político español: la puesta al día del régimen basada en el mantenimiento de sus principios fundamentales (el continuismo); la asunción de los estándares democráticos occidentales a partir del respeto a los procedimientos de la legalidad franquista (la reforma); o la constitución de gobiernos provisionales de concentración democrática - a escala estatal, regional, y municipal - y la apertura de un proceso constituyente que cancelase por completo el legado político franquista (la ruptura). Esta triple perspectiva incidió de lleno en la cuestión regional valenciana y en los posicionamientos políticos adoptados al respecto, entre 1975 y 1977, por una serie de profesores universitarios implicados en la oposición democrática ${ }^{12}$. Frente al continuismo, unos prefirieron la reforma y otros la ruptura, dicotomía que afectó de lleno a la concepción de lo que debería ser el futuro ente político valenciano. Para unos, se trataba de reformar las estructuras del Estado y superar el centralismo político-administrativo, desde el respeto a los procedimientos legales y el reconocimiento de la integridad de la nación española. Otros, en cambio, aceptaron el esquema de reforma del Estado, si bien trataron de dotar de una dimensión constituyente

sistencia y reacción (Valencia: Universidad de Valencia, tesis doctoral inédita, 2017); Juan Carlos Colomer Rubio, Gobernar la ciudad. Alcaldes y poder local en Valencia (1958-1979) (Valencia: Universidad de Valencia, 2017); Jaime Millás, Crónicas de la transición valenciana (1972-1985) (Valencia: Alfonso el Magnánimo, 2015); Patricia Gascó Escudero, La transición política en España: poder nacional y poder regional en UCD-Valencia, UCD-Castellón y UCD-Alicante (19761982) (Valencia: Universidad de Valencia, tesis doctoral inédita, 2015); Vicent Flor, coord., De país a comunitat. Valencianisme polític i regionalisme (Valencia: Afers, 2014); Ferran Archilés i Cardona, coord., Transició política i qüestió nacional al País Valencià (Valencia: Afers, 2010); Benito Sanz y Josep Maria Felip, 1962-1982. La construcción política de la Comunidad Valenciana (Valencia: Alfonso el Magnánimo, 2006); Benito Sanz y Francesc Romeu, eds., Memoria histórica de la transición y la democracia valenciana (Valencia: Universidad de Valencia, 2006); Juan Ferrando Badía (coord.), Estudio sobre el estatuto valenciano. El proceso autonómico (Valencia: Consell Valencià de Cultura, 1993) y Jesús Sanz, La cara secreta de la política valenciana. De la predemocracia al estatuto de Benicàssim (Valencia: Fernando Torres, 1982).

${ }^{12}$ Sobre la oposición democrática en el medio universitario valenciano, véase Ramon Aznar i Garcia, "Los diez de la Taula. Profesores valencianos en los inicios de la transición democrática”, en Universidades, colegios, poderes, coord. Jorge Correa Ballester (Valencia: Universidad de Valencia, 2021), 669-689; Pablo Cervera Ferri y Enrique Rodríguez Serrano, "La Facultad de Ciencias Económicas y Empresariales en la Transición (1971-1978)", en 50 años de la Facultat d'Economia de la Universitat de València, coord. Pablo Cervera Ferri (Valencia: Universidad de Valencia, 2017); Sergio Rodríguez Tejada, Zonas de libertad: dictadura franquista y movimiento estudiantil en la Universidad de Valencia (Valencia: Universidad de Valencia, 2009) y Benito Sanz, Rojos y demócratas. La oposición al franquismo en la Universidad de Valencia. 1939-1975 (Valencia: CCOO-PV, FEIS y Albatros, 2002). 
a la idea de Países Catalanes ${ }^{13}$. Una tercera variable — sin apenas incidencia electoral- planteó, al mismo tiempo, un programa de ruptura democrática y el reconocimiento de la pertenencia de los valencianos a la nación catalana.

En el ámbito universitario, ya en noviembre de 1975, una declaración de la Junta democrática de profesores no numerarios de la Facultad de Económicas, había exigido la toma en consideración de «los problemas y necesidades de un País Valenciano autónomo y democrático» ${ }^{14}$. Poco después, la declaración constitutiva del Consejo Democrático de la Universidad de Valencia reivindicó la necesidad de una ruptura democrática, que debería concretarse en la creación de una universidad autónoma, «al servicio del pueblo del País Valenciano oprimido nacional y socialmente» ${ }^{15}$. En este mismo sentido, el manifiesto «Por una universidad autónoma y democrática en el País Valenciano» situó en los primeros años sesenta del siglo XX el inicio del «proceso de reencuentro colectivo del pueblo valenciano, fruto del cual fue la obra fusteriana» y reivindicó «una coordinación preferente, por razones lingüísticas y culturales, con las demás universidades de los Países Catalanes» ${ }^{16}$. Otra declaración del Consejo, publicada en marzo de 1976 a raíz de la convocatoria de elecciones a rector, demandó el arraigo de la universidad a la «realidad social y nacional del País Valenciano» y la consecución de un estatuto de autonomía. La perspectiva adoptada era de ruptura, y se reivindicaba el «desmantelamiento de la actual estructura fascista a todos los niveles», la «dimisión de todos los cargos que han colaborado con el fascismo» y la apertura de un «proceso constituyente de elaboración de los nuevos estatutos» ${ }^{17}$.

\section{Reforma y regionalismo}

Entre las organizaciones de la oposición democrática valenciana, que hicieron suyo el planteamiento de reforma estatal en clave descentralizadora, y que con-

${ }^{13}$ Véase Pelai Pagès i Blanch, coord., La transició democràtica als Països Catalans, historia i memoria (Valencia: Universidad de Valencia, 2005).

14 “Declaració de la Junta Democràtica de P. N. N. d'Econòmiques. Comissió Promotora del Consell Democràtic de la Universitat de València (Econòmiques)", en Archivo de la Universidad de Valencia (AUV), Archivo Alfons Cucó, caja 23, carpeta 6.

15 "Declaració constituent del Consell Democràtic de la Universitat de València", en AUV, Archivo Alfons Cucó, caja 23, carpeta 6. Una aportación reciente en Josep Guia i Marín, "Consell Democràtic del País Valencià (1975-1976)", L’Espill, 65 (2021): 165-172.

16 "Per una universitat autònoma i democràtica al País Valencià", en AUV, Archivo Alfons Cucó, caja 23, carpeta 6 .

17 “Davant de l'elecció de rector", en AUV, Archivo Alfons Cucó, caja 23, carpeta 6. 
taron entre sus filas con profesores que desarrollaron una intensa actividad política entre 1975 y 1977 debemos mencionar a Demócratas Independientes del País Valenciano, Partido Socialista Popular, Partido Comunista del País Valenciano, Partido Socialista Obrero Español y Unión de Centro Democrático.

Manuel Broseta Pont, catedrático de Derecho Mercantil, presidente de la Junta Democrática del País Valenciano y —después- de Demócratas Independientes del País Valenciano (DIPV) no compartía la estrategia de la Taula de Forces Polítiques i Sindicals del País Valencià - la Taula - en cuya virtud la ruptura democrática española debía coincidir con la instauración de una Generalitat Valenciana provisional ${ }^{18}$. A su juicio, la presencia de la Taula en la comisión negociadora de la reforma política podía ser «útil para explicarle al presidente la problemática de los pueblos del Estado que, aun teniendo conciencia autonómica, no han disfrutado de un precedente histórico como Cataluña, el País Vasco y Galicia». Asimismo, se mostró firme partidario del llamado pacto estatutario, iniciativa - auspiciada también por los «independientes» Luis Font de Mora y Eliseu Climent- que trató de comprometer a los futuros diputados y senadores valencianos, de la izquierda y derecha democráticas, en la defensa de un estatuto de autonomía, que no un régimen administrativo especial ${ }^{19}$.

En opinión de Broseta, el País Valenciano constituía una nacionalidad, por razones históricas, culturales, económicas, políticas y lingüísticas ${ }^{20}$. Esta perspectiva fue tachada por el periodista Vicent Ventura de «autonomista de carácter más bien regionalista, parece que inspirada por el también profesor Ferrando» $\mathrm{y}$ "partidaria de soluciones autonómicas "a la italiana", que no federales» ${ }^{21}$. Poco después, el mismo periodista atribuyó un «trasfondo anticatalanista» al profesor "ahora autonomista», y una «alianza objetiva» con las «posiciones políticas fascistas» $»^{22}$. Y es que Broseta opinaba que la idea de

18 "Bastante trabajo tendremos en el País Valenciano para organizar correctamente la democracia en los momentos de ruptura como para que, al mismo tiempo, tengamos que preocuparnos de la organización de la Generalitat". Avui, 13-5-1976, p. 11 y La Vanguardia Española, 9-6-1976, p. 15.

${ }^{19}$ El pacto - considerado un error de cálculo por el periodista Vicent Ventura- no llegó a formalizarse. Avui, 22-1-1977, p. 11 y 30-4-1977, p. 13.

${ }^{20}$ Amadeu Fabregat, Partits polítics al País Valencià (Valencia: Tres i Quatre, 1976-1977, 2 vols.), I, 27-29.

${ }^{21}$ Vicent Ventura, "Eleccions a l'Ateneu: entrenament pre-democràtic", Avui, 11-2-1977, p. 12.

${ }^{22}$ A criterio del periodista, «la fiabilidad "valencianista" de los candidatos y los partidos» pasaba por su «aceptación del hecho nacional común a todos los Países Catalanes». Véase Avui, 8-3-1977, p. 12; V. Ventura, "El carnestoltes de la política valenciana", Avui, 11-3-1977, p. 10, y “País Valencià: per qui votar?”, Avui, 7-6-1977, p. 8. 
Países Catalanes podía originar una reacción peligrosa, no sólo de los actores del régimen -el llamado «búnquer barraqueta»-, sino también como respuesta primaria de un pueblo interesado en reencontrar su personalidad. Acerca de esta cuestión, insistirá:

\begin{abstract}
No creo en los «Países Catalanes». No creen tampoco el pueblo valenciano ni el pueblo catalán, salvo escasas minorías. Creo en la autonomía del País Valenciano, desligada de la de Cataluña. [...] Antes de consolidar la propia identidad valenciana creo perturbador - porque por incomprensión puede producir una alienación y una sensación negativa - plantear el tema de los Países Catalanes. En el plano lingüístico, creo positivo programar una acción coordinada - pero salvando las peculiaridades valencianascon el Principado y las Islas Baleares ${ }^{23}$.
\end{abstract}

En términos análogos se pronunció por entonces María Consuelo Reyna, subdirectora de «Las Provincias», sin duda el periódico más influyente de la región valenciana ${ }^{24}$. Sus declaraciones fueron reproducidas en un folleto editado por la Taula en el que se protestaba contra la línea editorial del diario. El organismo unitario de la oposición democrática quiso reivindicar el «concepto de Países Catalanes y su alcance, a la hora de analizar cuál es la nacionalidad del País Valenciano». Aquí las palabras de Reyna:

Valencia - País, Región o Reino- no tiene la menor conciencia de formar parte de una comunidad de Países Catalanes. Es más - para ser absolutamente sincera - creo que hasta la cuestión de la estricta autonomía no está totalmente clara a nivel popular. Tendrá que pasar un cierto tiempo hasta que se asimile, hasta que se comprenda. Sin embargo, Valencia tiene mucho que aprender de Cataluña. Nos falta que nuestros hombres políticos - del estamento oficial y de la oposición — sepan luchar con uñas y dientes como lo hacen los catalanes por lo suyo ${ }^{25}$.

Antes de las elecciones generales de junio de 1977, cierta prensa conjeturó acerca del posible nombramiento de Broseta como senador de designación real ${ }^{26}$. Sin embargo, las reticencias manifestadas por algunos partidos políticos valencianos frustraron aquella eventualidad ${ }^{27}$. Tras los comicios, el catedrático sostuvo que la cuestión autonómica era el problema «más grave y conflictivo» al que tenían que hacer frente los diputados y senadores elec-

\footnotetext{
${ }^{23}$ Destino,10-3-1977, p. 50.

${ }^{24}$ Véase Ana María Cervera Sánchez, Las Provincias y María Consuelo Reyna. Liderazgo y poder en tiempos de cambio (1966-1982) (Valencia: Universidad Autónoma de Barcelona, Universidad Jaume I de Castellón, Universidad Pompeu Fabra, Universidad de Valencia, 2020).

${ }^{25}$ Las Provincias, 3-2-1977, en AUV, Archivo Alfons Cucó, caja 23, carpeta 6.

${ }^{26}$ ABC Sevilla, 28-4-1977, p. 7 y La Vanguardia, 29-4-1977, p. 8.

${ }^{27}$ Dos y dos, 16-9-1977, p. 28.
} 
tos ${ }^{28}$. Dos eran los polos de tensión: o mera descentralización administrativa, o paso hacia el futuro Estado federal español y, entre uno y otro, había una variedad de posiciones intermedias. En Madrid, la situación revestía una especial gravedad, pues, en los medios decisión política, administrativa, financiera y militar, «el tema de la autonomía no se entiende, nada en absoluto». Es por ello que resultaban pertinentes unas reflexiones desde la «periferia». Y así sostuvo que la demanda autonomista formulada desde las nacionalidades y regiones no debía concebirse únicamente como una legítima reacción ante los excesos del centralismo franquista, sino también como «una reivindicación que nace de su propia naturaleza de pueblos y regiones, y del inalienable derecho que ostentan a buscar y a encontrar una forma de autogobierno que respete, dentro del Estado español (y, por lo tanto, sin separatismos) su propia realidad social, política, histórica y cultural» ${ }^{29}$. El nuevo estado democrático debía aunar el respeto de los derechos individuales de los ciudadanos y el respeto de los «pueblos, países y naciones del Estado español». No se trataba de «destruir la unidad del Estado, sino de conformarlo, de estructurarlo o de organizarlo de otra forma distinta: la más directa y la menos burocráticocentralizada posible». Los ejemplos italiano, alemán, norteamericano y suizo, entre otros, estaban ahí para confirmar la compatibilidad de la unidad estatal y el respeto de la identidad de los pueblos y regiones que los forman:

Hoy, nadie que quiera ser objetivo y respetuoso con la voluntad popular, además de con la historia y la cultura de los pueblos españoles, puede desconocer que el País Vasco, o Cataluña, o Galicia, o el País Valenciano poseen una identidad propia. Esa propia identidad no es folklórica, sino que ha de reflejarse en lo político: reconociendo su propia autonomía. El vasco, el catalán, el gallego, el valenciano quiere autogobernarse (y no que lo gobiernen en todo desde Madrid) en la esfera de las competencias que la futura Constitución democrática establezca.

A finales de 1977, Broseta prologó el libro Volem l'estatut, escrito por Vicent Franch, Lluís Aguiló y Manuel Martínez Sospedra - los tres vinculados al Departamento de Derecho Político de la Universidad de Valencia-. La obra contenía una historia de la reivindicación autonómica, estudiaba las diversas regulaciones constitucionales de la materia, avanzaba problemáticas

\footnotetext{
${ }^{28}$ Manuel Broseta Pont, “Las exigencias autonómicas”, Triunfo, 18-6-1977, pp. 26-27.

${ }^{29}$ En opinión de Broseta, «el centralismo no ha sido capaz de reducir, ni de evitar, el único problema que puede justificarlo: los desequilibrios sociales y económicos entre las regiones españolas ricas y pobres. Por el contrario, el centralismo, aliado con el poder económico, ha producido un éxodo de éstos, los pueblos pobres hacia los ricos, y ha impuesto un usufructo de los más desarrollados sobre los menos desarrollados».
} 
del futuro ente regional - traspaso de poderes, competencias y cooficialidad idiomática, entre otras-, y todo ello desde un planteamiento abierto «a ideas que ni nos gustan ni compartimos, pero que también están arraigadas en la sociedad» —afirmó uno de los autores ${ }^{30}$.

También Manuel Sánchez Ayuso hizo suya la reivindicación autonomista. Catedrático de Política Económica y presidente de la federación valenciana del Partido Socialista Popular (PSP), fue nombrado, en 1976, decano de la Facultad de Ciencias Económicas y Empresariales de la Universidad de Valencia. Con ocasión del III congreso del partido, participó destacadamente en la elaboración de la ponencia «Cuestión de las nacionalidades y regiones en el Estado Español». En ella se reconocía el derecho de las comunidades a reivindicar y proteger sus propios intereses, se rechazaba el nacionalismo desintegrador, se postulaba la representación territorial en una cámara alta y en un tribunal de garantías, y se denunciaban las desigualdades territoriales. A raíz de esta ponencia, el congreso del PSP aceptó la enmienda presentada por la delegación valenciana, en cuya virtud el partido se comprometió a asumir las reivindicaciones autonomistas de las plataformas unitarias de la oposición democrática ${ }^{31}$. No obstante, Sánchez Ayuso era ya consciente de que Coordinación Democrática echaba en falta un precedente histórico claro en la reivindicación estatutaria valenciana.

Aun cuando no se pronunció sobre el carácter nacional o regional del País Valenciano, el PSP consideraba que «lo importante era la defensa de la personalidad de los valencianos como pueblo, y su concreción en una serie de políticas específicas ${ }^{32}$. Es por ello que calificó la tesis de los Países Catalanes como un "grave obstáculo al proceso de concienciación del País Valenciano» ${ }^{33}$. Desde su punto de vista, no había razón alguna para apoyar esta idea política — cosa distinta era su dimensión lingüística一. De este parecer era asimismo Víctor Fuentes Prósper, profesor de Política Económica y secretario general de la federación valenciana del PSP, en cuyo nombre actuó en diversos actos de la Taula ${ }^{34}$. Durante el curso académico 1975-1976, participó activamente en diversas acciones de protesta impulsadas por el colectivo de profesores no numerarios de la Universidad de Valencia ${ }^{35}$. Este

${ }^{30}$ Mediterráneo, 29-12-1977, p. 6.

${ }^{31}$ Avui, 8-6-1976, p. 11.

${ }^{32}$ Amadeu Fabregat, "No som un partit sucursalista", en Dos y dos. Quatre, 22-8-1976, p. 5.

${ }^{33}$ Avui, 12-6-1976, p. 9.

${ }^{34}$ La Vanguardia Española, 21-7-1976, p. 10 y Avui, 8-12-1976, p. 14.

${ }^{35}$ Víctor Fuentes, "El curso académico 1975-1976 en la Universidad de Valencia y el movimiento de Profesores No Numerarios (P.N.N.s)", en El País Valenciano frente a la democracia, 
colectivo hizo suya la reivindicación de un «País Valenciano autónomo y democrático» ${ }^{36}$.

Sánchez Ayuso encabezó la lista de Unidad Socialista a las elecciones al Congreso de los Diputados de junio de 1977 por la circunscripción de Valencia. Según declaró, «el reconocimiento a las distintas nacionalidades del derecho a dotarse de un estatuto de autonomía» era uno de los cuatro objetivos de la coalición, junto con la elaboración de una constitución democrática, la legalización de los partidos que aún no lo habían sido, y la amnistía total ${ }^{37}$. Tras su elección como diputado, cesó como decano de la Facultad de Económicas ${ }^{38}$.

Emèrit Bono Martínez, profesor de Política Económica y destacado dirigente del PCE, adoptó el marco espacial regional en su labor investigadora $^{39}$. De aquí su participación en la obra colectiva L'estructura econòmica del País Valencia ${ }^{40}$. A su modo de ver, las masas populares no tenían conciencia de la necesidad de institucionalizar políticamente el País Valenciano, el cual, aun cuando no se trataba de una nacionalidad, podía llegar a serlo en el momento en que la identidad valenciana se afirmase en el marco democrático español. Entre los años cuarenta y sesenta, la actitud del PCE respecto a la reivindicación autonómica valenciana había sido «un punto inflexible» y «escasamente permeable». No obstante, la situación había cambiado radicalmente desde comienzos de la década de los setenta y la organización, aun con divergencias internas, buscaba una actitud propia y una respuesta adecuada al «problema valenciano» ${ }^{41}$.

Encabezó la lista del PCPV al Congreso por la circunscripción de Valencia en las elecciones de junio de 1977 y, durante la campaña, declaró que «la

dir. y coord. Juan Antonio Tomás Carpi (Valencia: PCPV, 1977, 2 vols.), I, 102-112. Asimismo, Avui, 6-11-1976, p. 10; y Sanz, Rojos y demócratas, 278

36 “Declaración de la Junta Democrática de PNN de Económicas. Comisión promotora del Consejo Democrático de la Universidad de Valencia (Económicas). Noviembre de 1975". AUV, Archivo Alfons Cucó, caja 23, carpeta 6.

${ }^{37}$ Mediterráneo, 20-5-1977, p. 11.

${ }^{38}$ Mediterráneo, 23-9-1977, p. 6.

${ }^{39}$ Vicent Ventura, "Diferencia entre la Valencia industrial real y la que ofrecen algunos organismos económicos”, La Vanguardia Española, 6-7-1972, p. 11.

${ }^{40}$ «Aparece en un momento sumamente oportuno. Viene a ser como un balance de los últimos treinta años, décadas importantes a raíz de las cuales la personalidad de toda una región se ha conformado típicamente, pero sin perder de vista un futuro desarrollo que aparece ya inmediato con las nuevas oportunidades a escala supranacional en donde tanto ha de jugar Europa y, sobre todo, en un clima de recuperación histórica y toma de conciencia por las soluciones regionales», en La Vanguardia Española, 22-4-1971, p. 56.

${ }^{41}$ A finales de 1976, se anunció la constitución del Partido Comunista del País Valenciano. Avui, 2-12-1976, p. 11. 
conciencia nacional es una prueba de que estamos retomando nuestro camino», que los comunistas estaban empeñados en que «este pueblo nuestro se ponga en marcha, reencuentre su identidad», y que existía la esperanza de «darle a nuestro pueblo una estructuración autonómica que le permita ser cada vez más dueño de su destino ${ }^{42}$. Tras resultar elegido diputado, incidió en las ideas de la consideración del caso valenciano como una derivada del futuro proceso general de regionalización estatal, y como una dinámica de recuperación identitaria ${ }^{43}$. Asimismo en consonancia con lo que había sido la línea política defendida por el PCE, insistió en distinguir los procesos autonómicos valenciano y catalán, y dijo:

Hay diferencias obvias. No tenemos la misma tradición respecto al Estatuto, y el nivel de conciencia popular no es tan acusado. Nosotros lo que podemos hacer es ir prefigurando cosas. No alcanzamos a pedir, como han pedido ya casi todas las fuerzas de Cataluña, que se conceda una especie de autogobierno directo a todos los niveles. En nuestro caso, sería quemar un tiempo y unas etapas que no nos pertenecen todavía. No quiere decir esto que dentro de un tiempo las cosas no puedan cambiar ${ }^{44}$.

Tampoco le parecían equiparables las negociaciones iniciadas entre los parlamentarios catalanes y el gobierno Suárez, y unas posibles conversaciones entre las autoridades gubernamentales y el Plenario de Parlamentarios del País Valenciano. Y señaló: «No se ve esa posibilidad. Pero, en la medida en que en Cataluña se resuelvan las cosas de forma democrática y positiva, se abriría para nosotros un camino y una innegable ayuda».

Antonio Vicente Sotillo Martí, militante del PSOE, se incorporó en 1976 al Departamento de Derecho Mercantil de la Universidad de Valencia, una vez concluida su estancia como becario en el Colegio de San Clemente de los Españoles, en Bolonia ${ }^{45}$. Elegido diputado por Castellón, declaró: «empujaremos el estatuto de autonomía» ${ }^{46}$. En su calidad de miembro de las comisiones de Constitución y de Reglamento del Congreso de los Diputados, se pronunció a favor del «respeto a la peculiaridad de cada nacionalidad o re-

${ }^{42}$ Mundo Obrero. Órgano Central del Partido Comunista de España, 16-5-1977, p. 5 y 13-61977, p. 4.

43 "Los comunistas valencianos del PCPV pretendemos ir hacia un proceso constituyente en el que se aborde el estatuto para el País Valenciano, al igual que para otras nacionalidades y regiones del Estado. El pueblo valenciano irá así recuperando su identidad», en Mundo Obrero. Órgano Central del Partido Comunista de España, 16-6-1977, p. 4.

${ }^{44}$ Mundo Obrero. Órgano Central del Partido Comunista de España, 9-8-1977, p. 4.

${ }^{45}$ A instancias de Manuel Broseta, Sotillo defendió su segunda tesis doctoral en Derecho, en enero de 1978. Mediterráneo, 22-1-1978, p. 3.

${ }^{46}$ Avui, 22-6-1977, p. 5. 
gión diferenciada que integra el Estado español», y reconoció que «los procesos de autonomía [...] son también un tema constitucional importante sobre el cual el partido está totalmente volcado $»^{47}$. Esta sensibilidad autonomista también quedó acreditada con ocasión de las primeras gestiones encaminadas a la creación de una universidad en Castellón. Se quería integrar al Colegio Universitario de Castellón en el Patronato de la Universidad de Valencia, el cual - dijo- «no debe ser el patronato de una ciudad - Valencia- sino de todo el País Valenciano» ${ }^{48}$. A su juicio, no resultaba admisible una regionalización de índole meramente administrativa, pues «el pueblo no debe ser simple receptor de la autonomía, sino participar democráticamente en su desarrollo, a través de actos públicos, y expresión por medio del sufragio ${ }^{49}$. Antes incluso de que la Constitución estableciese un «un régimen pleno de autonomía", consideraba conveniente que:

[...] se vayan ensayando regímenes preautonómicos, porque eso inicia un rodaje que será muy interesante y formativo no sólo para los políticos que el día de mañana tengan que representar al País Valenciano, sino que además también lo será para el pueblo en general. De esta forma nos iremos acostumbrando a resolver los problemas por nosotros mismos y ensayando lo que en su momento será una autonomía plena ${ }^{50}$.

Manuel Sánchez Ayuso, Emèrit Bono y Antonio Sotillo formaron parte de la comisión del Plenario de Parlamentarios del País Valenciano encargada de negociar con el Gobierno la instauración del régimen preautonómico ${ }^{51}$. Sotillo participó en Castellón, junto con Lluís Aguiló Lucia y Vicent Pitarch Almela, en la mesa redonda «La Constitución Española y el Estatuto de Autonomía», organizada por el Consell Popular de Cultura de Castelló y el Secretariat de l'Ensenyament de l'Idioma ${ }^{52}$. Por entonces, se estaba discutiendo en el Congreso de los Diputados la redacción del título VIII de la Constitución, y Sotillo expuso el sentido de las principales enmiendas planteadas por el $\mathrm{PSOE}^{53}$.

Luis Gámir Casares resultó elegido diputado en las listas de UCD durante las elecciones generales de 1977 por la circunscripción de Alicante.

${ }^{47}$ Mediterráneo, 30-7-1977, p. 5.

${ }^{48}$ Mediterráneo, 11-7-1977, p. 5. A este respecto, ha de tenerse en cuenta que, poco después, Sotillo fue nombrado representante del Plenario de Parlamentarios del País Valenciano en el Patronato de la Universidad de Valencia. Mediterráneo, 29-11-1977, p. 2.

${ }^{49}$ Mediterráneo, 9-10-1977, p. 3.

${ }^{50}$ Mediterráneo, 16-11-1977, p. 5.

${ }^{51}$ Mediterráneo, 22-11-1977, p. 8.

${ }^{52}$ Mediterráneo, 20-1-1978, p. 6.

${ }^{53}$ Mediterráneo, 21-1-1978, p. 7. 
Había sido profesor agregado de Política Económica de la Universidad Complutense de Madrid y era catedrático de la asignatura en la Universidad de Santiago de Compostela ${ }^{54}$. Con el gobierno de Arias Navarro, fue nombrado subdirector general de Estudios y Ordenación de Estructuras Comerciales, y declaró: «el sector más inteligente del capitalismo español está a favor de la evolución política» ${ }^{55}$. Tras la designación de Adolfo Suárez como Presidente del Gobierno, fue nombrado secretario general técnico del Ministerio de Agricultura, regentado a la sazón por Fernando Abril-Martorell, quien adquiriría, tiempo después, un destacado protagonismo en la política valenciana ${ }^{56}$. Miembro del Consejo Político del Partido Social Demócrata, Gámir se declaró partidario de la reforma fiscal y del desarrollo de los impuestos directos, «para no perjudicar como hasta ahora a la clase trabajadora» ${ }^{57}$. Formó parte de la Comisión de Economía y Hacienda del Congreso de los Diputados y fue nombrado presidente del Banco Hipotecario de España ${ }^{58}$. Poco después, fue elegido presidente del Club Convergencia, entidad con la finalidad declarada de «colaborar al logro de una mayor responsabilidad y solidaridad en la sociedad española», y comprometida en «ofrecer una información más directa, crítica, amplia y actual $»^{59}$. Aun cuando por su condición de diputado formó parte del Plenario de Parlamentarios del País Valenciano, no intervino en el debate público sobre la cuestión autonómica.

\section{Reforma y catalanismo}

El Partido Socialista del País Valenciano (en proceso de convergencia) fue la organización política valenciana más representativa de lo que podría calificarse como reformismo catalanista. Entre sus dirigentes, el partido contó con tres profesores universitarios con responsabilidades orgánicas e institucionales entre 1975 y 1977.

Ernest Lluch Martín, profesor agregado de Historia de las Doctrinas Económicas y autor de La vía valenciana, sostuvo —en contra de lo afirmado

${ }^{54}$ BOE de 17-9-1975, p. 19.676 y BOE de 1-4-1977, p. 7.340.

${ }^{55}$ BOE de 29-3-1974, p. 6.431; Hoja del lunes de Barcelona, 22-3-1976, p. 14 y Mediterráneo, 30-4-1976, p. 16.

${ }^{56}$ BOE de 24-7-1976, p. 14.346, y Mediterráneo, 24-7-1976, p. 9.

${ }^{57}$ Flores y Abejas. Semanario de información de la provincia de Guadalajara, 4-1-1977, p. 8.

${ }^{58}$ BOE de 26-10-1977, p. 23.510, y Diario de Burgos, 16-10-1977, p. 14.

${ }^{59}$ De la junta directiva formaban también parte Óscar Alzaga, César Menéndez Roces, Gabriel Elorriaga, Fernando Ybarra y Jesús Ubierna. Hoja del lunes de Madrid, 26-12-1977, p. 6. 
por Joan Fuster- que el País Valenciano «ha sido un país con política, política de una burguesía sólida y coherente» y que «es el país del Estado español que más ha cambiado durante los diez o quince últimos años» ${ }^{60}$. A su juicio, uno de los factores más destacados de esta transformación era el creciente influjo del valencianismo ${ }^{61}$. La intelectualidad, el valencianismo y el obrerismo estarían siendo, pues, los tres grandes motores de la democratización valenciana ${ }^{62}$. A pesar de la rápida transformación, Lluch consideraba que había condiciones de arraigo del nacionalismo que, en el caso valenciano, se habían dado sólo tardíamente; a saber: una propiedad agraria igualitaria y un predominio del comercio agrario de carácter exportador ${ }^{63}$. No obstante, se mostró contrario al veto del PSUC a una de las reivindicaciones esenciales de la Taula: la creación inmediata de una Generalitat Valenciana provisional ${ }^{64}$. En este sentido, sostuvo que la oposición democrática valenciana - también el PCE - había alcanzado un acuerdo de mínimos alrededor de las reivindicaciones de libertad, amnistía, estatuto de autonomía y sindicato obrero. Ahora, dicha negativa suponía la desautorización de los compromisos alcanzados por los comunistas valencianos y el inicio de una espiral de discriminaciones estatutarias. En cuanto a la tesis de la catalanidad nacional de los valencianos, Lluch insistió en el «estado fluido y evolutivo de la conciencia de Países Catalanes» y consideró erróneo e infantil — como hacía el PSANactuar como si la unidad y la homogeneización cultural y política fuesen algo evidente. Sobre esto afirmó:

Somos por el contrario bien conscientes de cómo, desde el siglo XVI, fue disminuyendo la conciencia unitaria y, por lo tanto, la acentuación de las diferentes conciencias regionales, facilitada al actuar sobre zonas con una personalidad fuerte, no reducible en todo caso a un País Valenciano librecambista y a una Cataluña proteccionista ${ }^{65}$.

\footnotetext{
${ }^{60}$ Amadeu Fabregat, "Ernest Lluch i el gran canvi del País Valencià", Avui, 1-6-1976, p. 11. Un estudio reciente sobre la actividad política de Lluch durante el periodo analizado en Marc Baldó Lacomba, "Ernest Lluch, intelectual comprometido de la generación del consenso", en Universidad y sociedad: historia y pervivencias, coord. Jorge Correa Ballester (Valencia: Universidad de Valencia, 2018), 63-83.

${ }^{61}$ Rafael Ventura Melià, "Ernest Lluch”, Destino, 17-6-1976, pp. 54-55.

${ }^{62}$ Rafael Ventura Melià, "Presentació del sindicalisme valencià", Avui, 9-7-1976, p. 9.

${ }^{63}$ Dos y dos. Quatre, 28-11-1976, p. 2.

${ }^{64}$ Véase Avui, 23-7-1976, p. 6 y Ernest Lluch, "Estatuts sense exclusions", Avui, 24-8-1976, p. 3.

${ }^{65}$ Ernest Lluch, "Els Països Catalans (I). Un procés unitari i divers", Dos y dos. Quatre, 6-41977, pp. 19-20 y “Els Països Catalans (i II). Tres postures polítiques”, Dos y dos, 20-4-1977, pp. 17-18.
} 
A su juicio, entre 1959 y 1962, la conciencia compartida había crecido «con una fuerza que nunca había tenido anteriormente» y consideraba que «el valencianismo aislacionista» no había hallado «ningún eco entre los jóvenes hasta su desaparición total a finales de la década de los 60». La idea de Países Catalanes debía concebirse, pues, como una problemática política que requería de maduración, coordinación y voluntad popular. Y todo ello sin obviar las resistencias que, además de cierta burguesía proclive a las tesis centralistas, oponían amplios segmentos populares, de inmigrantes y de residentes en las comarcas castellanoparlantes. En junio de 1977, Lluch encabezó la lista de la coalición Socialistas de Cataluña a las elecciones al Congreso de los Diputados por la circunscripción de Girona y, a partir de este momento, quedó formalmente al margen del proceso estatuyente valenciano.

Alfons Cucó Giner, profesor de Historia Universal Contemporánea y dirigente asimismo del PSPV (en proceso de convergencia) experimentó una evolución ideológica que le condujo al socialismo y la defensa de la catalanidad de los valencianos. Rompió así con quienes, en 1960, habían editado su poemario Lluernes tan sols ${ }^{66}$. Su estudio Le mouvement nationaliste en Catalogne: (region valencienne et Baléares) expresó bien esta nueva orientación ${ }^{67}$. Su tesis de doctorado, El valencianisme polític, 1874-1936, fue elogiada por Miguel Artola, quien la calificó de «trabajo es de importancia primordial, porque saca la vida política valenciana de la total obscuridad en que se encontraba, circunstancia que no es precisamente una excepción en nuestro país» ${ }^{68}$. No fue del mismo parecer, en cambio, Enrique Thomas de Carranza, director general de cultura popular y espectáculos, quien emitió una resolución desaconsejando su edición ${ }^{69}$. Por su parte, Joan Fuster la consideró como una «aportación de extraordinario interés» y «papel de lectura fascinante»; mientras que Ricardo de la Cierva —a la sazón jefe del gabinete de estudios sobre historia del Ministerio de Información y Turismo- le recriminó el falseamiento del marco histórico ${ }^{70}$. También Baltasar

${ }^{66}$ Destino, 24-12-1960, p. 93 y 20-8-1966, p. 35.

${ }^{67}$ La Méditerranée de 1919 à 1939. Actes du Colloque organisé par le Centre de la Méditerranée moderne et contemporaine, 28-31 mars 1968 (Paris: SEVPEN, 1969).

${ }^{68}$ Carta de 17 de abril de 1970. AUV, Archivo Alfons Cucó, caja 1, carpeta 59.

${ }^{69}$ La resolución del director general de cultura popular y espectáculos, 23 de mayo de 1970, en AUV, Archivo Alfons Cucó, caja 1, carpeta 62.

${ }^{70}$ Joan Fuster, "Medio siglo de historia difícil", Destino, 7-8-1971, p. 50. Alfons Cucó le negó a De la Cierva «cualquier autoridad para hablar con seriedad sobre historia del País Valenciano». Véase Alfons Cucó, “Obligada respuesta a Ricardo de la Cierva”, Destino, 5-2-1972, p. 17. 
Porcel terció en la polémica y se refirió a la «aportación insoslayable» que suponía esta investigación ${ }^{71}$.

Cucó sostenía que entre los valencianos había una constante histórica de reivindicación de la autonomía política ${ }^{72}$. Y, frente al argumento historicista de la tramitación parlamentaria de los estatutos catalán, vasco y gallego durante la II República, propuso el contraargumento de la existencia, en 1936, de un principio de acuerdo estatutario entre los representantes de las tres provincias valencianas ${ }^{73}$. Asimismo, distinguía entre el «sucursalismo» y el «mimetismo» generalizados en tiempos del liberalismo decimonónico, y el valencianismo democrático surgido con la instauración de la II República Española. A raíz de las elecciones generales de 1936, el Frente Popular había posibilitado un conglomerado autonomista de partidos de centro e izquierda, que propició la redacción de varios anteproyectos de estatuto. Pero, tras el estallido de la Guerra Civil, el «tacticismo» del PSOE y del PCE frustró aquellas iniciativas autonomistas - sostuvo $^{74}$. Coincidía con Ernest Lluch en que la sociedad valenciana había experimentado, desde comienzos de los años sesenta, una honda transformación hacia una realidad socio-política muy «fluida» y «compleja». Y sostenía que:

La autonomía se presenta - tras la espectacular toma de conciencia nacional del pueblo valenciano de los últimos años- no sólo como una vía de recuperación nacional, sino, además, como un instrumento de profundización de la democracia y, también, como medio de defensa popular ante la colonización del sector público realizado básicamente a través del Estado ${ }^{75}$.

Desde esta óptica, no le parecía «demasiado exacto» considerarla como hacía Joan Fuster- un «país sin política» ${ }^{76}$. También discrepó con En-

\footnotetext{
${ }^{71}$ Baltasar Porcel, "Ir y venir", Destino, 9-11-1974, p. 17.

72 Alfons Cucó, “Quan el mal ve d'Almalsa..., Dos y dos, 16-5-1976, pp. 7-8 y, del mismo autor, "Sobre l'Autonomia al País Valencià: nota prèvia", Avui, 27-5-1976, p. 3.

${ }^{73}$ Alfons Cucó, Estatutismo y valencianismo (Valencia: Fernando Torres, 1976), 27 y 74. Sobre el acuerdo estipulado, el 2 de noviembre de 1936, entre diferentes fuerzas políticas valencianas, véase el diario El Liberal, 22-11-1936, p. 4. Según recordaba Vicent Ventura, «se había llegado a un solo texto para el área territorial coincidente con la del País Valenciano», en "Libros y conferencias contra manipulaciones", La Vanguardia Española, 17-7-1976, p. 6. Una reciente puesta al día en María Pilar Hernando Serra, Una historia inacabada. El autonomismo valenciano de los años treinta (Valencia: Tirant lo Blanch, 2021.

${ }^{74}$ Alfons Cucó, "Les dificultats (històriques) del valencianisme", Avui, 4-8-1976, p. 3 y "Autonomia i espai polític valencià", Avui, 1-9-1976, p. 3.

${ }^{75}$ Alfons Cucó, “També volem l'estatut", Triunfo, 8-10-1977, p. 29.

${ }^{76}$ Alfons Cucó, "Una alternativa socialista”, Avui, 15-9-1976, p. 3.
} 
rique Tierno y Santiago Carrillo a propósito de la dicotomía regionalismo/ nacionalismo ${ }^{77}$. Y con la sociedad cultural Lo Rat Penat, a la que recriminó que nunca hubiese ofrecido una «alternativa global —ni cultural ni políticamente- al statu quo imperante en el País Valenciano» ${ }^{78}$.

El PSPV (en proceso de convergencia) pertenecía a la Coordinadora Socialista de los Países Catalanes, así como a la Federación de Partidos Socialistas, que reclamaba la plena soberanía de las distintas «áreas nacionales o regionales» españolas y la solidaridad en el «marco general del Estado» ${ }^{79}$. No obstante, Cucó se mostró escéptico acerca de las posibilidades reales de un futuro político conjunto que, en todo caso, debería ajustarse a la fórmula confederal. Cucó era consciente de las dificultades que lastraban las relaciones entre Barcelona y Valencia, las dos principales urbes del mediterráneo peninsular. Ya en 1971, Lluís Aracil - sociolingüista que realizaba una estancia de investigación en la Universidad de Standford e intercambiaba cartas con el historiador Stanley G. Payne- le hizo partícipe de sus consideraciones al respecto: For a century or so, the position of the Valencian Country vis a vis Catalonia and Spain (or Castile) has been piquantly ambiguous; the historical decalage between the Valencian Country and Barcelona has had something to do with a phenomenon which is otherwise from unique -cf. the Czecho-Slovak instance, y Valencian (anti-Barcelonese) parochialism has irrepressibly persisted in choosing language as a battle-field ${ }^{80}$. Unos años después, también Miquel Batllori, director del Archivo Histórico de la Compañía de Jesús, en Roma, le trasladó su punto de vista sobre:

La diferente situación social del País Valenciano durante los siglos XIX y XX condiciona una diferente actitud política y cultural que la contemporánea del Principado. Y eso vale igualmente para los siglos XV y XVI, a pesar de la unidad de la lengua, que no implica uniformidad de cultura y civilización. Es precisamente esta diversidad la que da una gran variedad a la historia política, social y cultural de nuestros países y elimina cualquier sucursalismo ${ }^{81}$.

Sin duda, estos pareceres influyeron en los planteamientos de Cucó, quien rechazó el «maximalismo nacionalista de algunos» y propugnó «aislar el caso del País Valenciano de los demás Países Catalanes» ${ }^{82}$. Tras las elecciones

\footnotetext{
${ }^{77}$ Alfons Cucó, "Primera i segona divisió", Avui, 13-10-1976, p. 3.

${ }^{78}$ Alfons Cucó, "Ratpenatisme i valencianisme", Avui, 23-6-1976, p. 3.

${ }^{79}$ Avui, 26-6-1976, p. 7.

${ }^{80}$ AUV, Archivo Alfons Cucó, caja 1, carpeta 100.

${ }^{81}$ AUV, Archivo Alfons Cucó, caja 1, carpeta 198.

${ }^{82}$ Avui, 1-1-1977, p. 11, 4-1-1977, p. 2 y 27-11-1977, p. 9.
} 
generales de 1977, refiriéndose al PSPV, declaró que «sin duda alguna, ocupamos un protagonismo político en el País Valenciano muy superior al que corresponde a un partido extraparlamentario» ${ }^{83}$. Poco después, se firmó el acuerdo de fusión con el PSOE - el partido que obtuvo el mayor número de escaños en las circunscripciones valencianas-, en el que se partía de «la constatación del carácter plurinacional del Estado Español», se afirmaba que «la relación entre las diversas nacionalidades no es de igualdad sino de opresión de una sobre las otras» y, por un lado, se sostenía que «el País Valenciano es una comunidad política diferenciada, con plena personalidad» y, por otro, se hacía referencia al «reconocimiento [de] la comunidad de vínculos lingüísticos, culturales, históricos y sociales entre el País Valenciano, las Islas y Cataluña, que para el PSPV implica la existencia de una comunidad nacional llamada Países Catalanes ${ }^{84}$.

Vicent Soler i Marco, profesor de Estructura Económica formado bajo la tutela de Ernest Lluch y Emèrit Bono, era también un destacado militante del PSPV. A propósito de la idea de Países Catalanes, polemizó con el historiador catalán Josep Fontana, quien advertía del peligro de pretender construir una conciencia nacional sobre la sola base de la lengua y la historia, lo que comportaría una catalanidad tan «vacía y estéril» como lo era la noción de hispanidad. Este razonamiento llevó a Soler a situar a Fontana junto al «búnker más recalcitrante de Valencia» ${ }^{85}$. En opinión del primero, la clase dominante valenciana se caracterizaba por un «furibundo españolismo anticatalanista». Ahora bien - argumentaba Soler-, había otras ciudades valencianas que estaban «en íntima conexión» con Barcelona y que tenían en el puerto de esta ciudad la base de la «reexportación de sus productos a ultramar». Era el caso asimismo de las comarcas septentrionales valencianas, que habían tenido a Reus como capital económica. A su modo de ver, la realidad era compleja y no se compadecía con una supuesta dualidad estructural entre Valencia y Cataluña, instrumentalizada por las clases dominantes, y que ahora resultaba validada por el análisis de Fontana. Y se preguntaba:

¿Por qué la gente de Tortosa es de «nación» catalana y la de Vinaroz no? ¿Por qué los agraristas de Reus o de Lleida son de nación catalana y los industriales de Ontinyent o Alcoy no? ¿Qué grado de interdependencia determina los límites nacionales? ¿No hay más diferencias entre la Cataluña Vieja y la Nueva que entre esta última y las comarcas del norte del País Valenciano?

\footnotetext{
${ }^{83}$ AUV, Archivo Alfons Cucó, caja 12, carpeta 56.

${ }^{84} \mathrm{El}$ documento, con rúbricas de los firmantes, data del 5 de enero de 1978. AUV, Archivo Alfons Cucó, caja 12, carpeta 63.

${ }^{85}$ Avui, 12-10-1976, p. 6.
} 
En síntesis, Soler consideraba que el planteamiento «excesivamente economicista» de Fontana conducía a la errónea identificación entre los marcos nacional y estatal españoles ${ }^{86}$. Un año antes, había formado parte del equipo de investigadores que ganó el premio Joan Fuster de ensayo de 1975 por el trabajo titulado Pèls $i$ senyals, en el que se analizaba la «tergiversación de la historia del País Valenciano por parte del búnker más recalcitrante» ${ }^{87}$.

\section{Ruptura y catalanismo}

El Partit Socialista d'Alliberament Nacional dels Països Catalans (PSAN) hizo suya la estrategia de la ruptura democrática y de la asunción del independentismo de la nación catalana, en la que consideraba englobado al País Valenciano. La organización no fue legalizada hasta el mes de septiembre de 1977 y, por lo tanto, no concurrió en las elecciones generales que resultaron constituyentes $^{88}$. Dos de sus principales dirigentes fueron profesores de la Universidad de Valencia.

Josep Lluís Blasco Estellés, profesor de Teoría del Conocimiento, concebía a los partidos políticos como la vanguardia de las masas populares, a España como un Estado plurinacional y al País Valenciano como parte integrante de la nacionalidad catalana, la cual —-sostendrá- estaba políticamente alienada ${ }^{89}$. «No comprendo aquello del País Valenciano como nación; no lo ha sido nunca, ni hay ninguna razón seria para hablar de una nación valenciana; desde una óptica nacionalista sólo hay Países Catalanes» —afirmó, en octubre de $1976-{ }^{90}$. Partidario del anteproyecto de estatuto denominado de Elche -que preveía la segregación territorial de las comarcas castella-

${ }^{86}$ Vicent Soler, “Una polèmica positiva”, Avui, 3-11-1976, p. 3.

${ }^{87}$ Avui, 26-10-1976, p. 10; 9-11-1976, p. 11 y 14-11-1976, p. 9. Asimismo, Rafael Ventura Melià, "Octubre, vendimia de premios", Destino, 4-11-1976, p. 46. También, La Vanguardia Española, 26-10-1976, p. 11.

${ }^{88}$ Avui, 11-9-1977, p. 8.

${ }^{89}$ «El rasgo fundamental de mi ideología es creer que los Países Catalanes constituyen una nación actualmente oprimida, y que la clase obrera, como única clase que puede construir la verdadera libertad una vez en el poder, tiene como misión objetiva la liberación de esta nación», en Fabregat, Partits polítics, II, 16-28. Sobre Blasco y con el interés añadido de haber sido elaborado por uno de los profesores analizados, véase Emèrit Bono Martínez, "En record de Josep Lluís Blasco", Braçal. Revista del Centre d'Estudis del Camp de Morvedre, 43 (2011): 59-62.

${ }^{90}$ Josep Maria Solé i Sabaté, "Taula rodona: El que volen els valencians", Canigó, 473 (1976): 20. 
noparlantes - constataba la existencia de una amplia demanda popular en favor de la autonomía ${ }^{11}$. La tesis de los Países Catalanes - como él mismo reconocía- era impulsada sobre todo por valencianos, pese a las reticencias de no pocos políticos catalanes. Blasco estaba al corriente de la crítica del marxismo mecanicista a dicha tesis, tachada de errónea por voluntarista e idealista. Frente a ello, argüía que la aceptación de la realidad podía devenir en reaccionaria y arribista, y que debía apostarse por un marxismo sincrético, que incidiese así en la noción de voluntad transformadora. En cualquier caso - sostendrá flemático- «si la teoría que hemos lanzado no arraiga en el pueblo es que nos hemos equivocado $»^{92}$.

Josep Guia Marín, profesor de la Facultad de Ciencias, asumió en 1976 la dirección del PSAN. Sostenía que el partido estaba «inventando» un «nuevo tipo de comunismo» necesario para «llevar adelante la estrategia de la lucha obrera de las naciones oprimidas en el seno de los Estados burgueses ${ }^{93}$. A su juicio, el País Valenciano era parte integrante de los Países Catalanes, concebidos a su vez como una verdad experimental ${ }^{94}$. «No hace falta demostrar lo que es una realidad: la pertenencia del País Valenciano a los Países Catalanes»-dijo Guia. También, que «la conciencia popular no es un elemento determinante para juzgar el hecho nacional $»^{95}$.

El PSAN se había declarado partidario de la llamada ruptura democrática - es decir, la conformación de gobiernos provisionales a escala estatal, regional y municipal, y la apertura de un proceso constituyente ${ }^{96}$. Una vez impuesto el esquema de negociación entre la oposición moderada y el gobierno de Suárez, y conocidos los resultados del referéndum de la ley para la reforma política, Guia declaró que «la actitud oficial durante la campaña del

${ }^{91}$ Blasco preparó la edición de Els estatuts del País Valencià, libro en el que defendía este anteproyecto de estatuto, elaborado junto a Joan Fuster, Eliseu Climent, Enric Solà y Rafael Ninyoles. Véase Josep Lluís Blasco Estellés, ed., Els estatuts del País Valencià (Barcelona: La Magrana, 1977). Una recensión en La Vanguardia, 24-11-1977, p. 50.

${ }^{92}$ Avui, 11-8-1976, p. 7.

${ }^{93}$ A. Fabregat, "Per un comunisme d'arrels nacionals. Entrevista amb Josep Guia, del PSAN, en la nova etapa de radicalització", Avui, 8-7-1976, p. 10 y "Tiempo político en el País Valenciano", Destino, 29-7-1976, pp. 44-45.

${ }^{94}$ Sabaté, "Taula rodona", 22. Unos meses más tarde, en el marco de unas Jornadas de debate sobre los Países Catalanes, celebradas en la Facultad de Derecho de la Universidad de Barcelona, Gustau Muñoz, militante valenciano del PCE, tachó de «entelequia» aquella noción política. Avui, 12-6-1976, p. 1. Sobre la significación y propósito de estas jornadas, véase Treball. Òrgan Central del Partit Socialista Unificat de Catalunya, 18-10-1976, p. 5.

${ }^{95}$ Destino, 11-3-1976), p. 43.

${ }^{96}$ Josep Guia, “Sense exclusions!", Avui, 26-8-1976, p. 3. 
referéndum y en el mismo recuento de las votaciones ha estado en la línea de manipulación de la más pura ortodoxia franquista ${ }^{97}$.

En octubre de 1977, participó - junto a Emèrit Bono y Alfons Cucó, entre otros- en el acto de clausura del ámbito de instituciones del Congreso de Cultura Catalana, celebrado en Castellón y en el que se conferenció sobre el estatuto y la Generalitat valencianos. Presidió el acto Andreu Abelló, diputado del PSC y miembro de la Asamblea de Parlamentarios de Cataluña ${ }^{98}$.

\section{Conclusiones}

En los primeros meses de la transición democrática, se consumó una quiebra en el seno del reformismo político valenciano entre dos concepciones nacionales distintas. En el debate político, hubo quien reivindicó la nacionalidad catalana de los valencianos y quiso asignarle a la idea de Países Catalanes una función constituyente. A ello se opusieron quienes aducían la falta de engarce de esta propuesta política con la voluntad social mayoritaria y con la propia historia institucional. La polémica - que hasta entonces había quedado circunscrita a limitados círculos intelectuales-se socializó y devino en el principal foco de tensión política. El proceso autonómico valenciano quedó así condicionado desde sus mismos comienzos.

\section{Bibliografía}

ARCHILÉS I CARDona, FerRAN, coord. Transició política i qüestió nacional al País Valencià. Valencia: Afers, 2010.

Aznar i Garcia, Ramon. "Los diez de la Taula. Profesores valencianos en los inicios de la transición democrática”. En Universidades, colegios, poderes, coordinado por Jorge Correa Ballester. Valencia: Universidad de Valencia, 2021.

- "Los inicios de la transición democrática valenciana", Revista Electrónica de Historia Constitucional, 21 (2020): 277-299.

- "L'exclusió valenciana de la reforma política española". En Els valencians, poble d'Europa. L'horitzó federal, editado por Joan Alfred Martínez i Seguí, August Monzon i Arazo y Francisco Javier Palao Gil. Valencia: Universidad de Valencia, 2019.

\footnotetext{
${ }^{97}$ Avui, 17-12-1976, p. 12.

${ }^{98}$ Avui, 16-10-1977, p.
} 
BALDó LACOMBA, MARC. "Ernest Lluch, intelectual comprometido de la generación del consenso". En Universidad y sociedad: historia y pervivencias, coordinado por Jorge Correa Ballester. Valencia: Universidad de Valencia, 2018.

Blasco Estellés, Josep Lluís, ed. Els estatuts del País Valencià. Barcelona: La Magrana, 1977.

Bono MARTínez, EMÈrit. "En record de Josep Lluís Blasco". Braçal. Revista del Centre d'Estudis del Camp de Morvedre, 43 (2011): 59-62

Cervera Ferri, Pablo y Rodríguez Serrano, Enrique. "La Facultad de Ciencias Económicas y Empresariales en la Transición (1971-1978)”. En 50 años de la Facultat d'Economia de la Universitat de València, coordinado por Pablo Cervera Ferri. Valencia: Universidad de Valencia, 2017.

Cervera SÁnchez, Ana María. Las Provincias y María Consuelo Reyna. Liderazgo y poder en tiempos de cambio (1966-1982). Valencia: Universidad Autónoma de Barcelona, Universidad Jaume I de Castellón, Universidad Pompeu Fabra, Universidad de Valencia, 2020.

Colomer Rubio, JuAn CARlos. Gobernar la ciudad. Alcaldes y poder local en Valencia (1958-1979). Valencia: Universidad de Valencia, 2017.

Cravatte, Henry. "La Conference Européenne des Pouvoirs Locaux". Annuaire Européen-European Yearbook, 10 (1962): 43-62.

Cucó, ALfons. Estatutismo y valencianismo. Valencia: Fernando Torres, 1976.

FABREgat, AMAdeu. Partits polítics al País Valencià. Valencia: Tres i Quatre, 1976-1977, 2 vols.

FERnÁNDEZ-CARVAJAL, Rodrigo. La Constitución Española. Madrid: Editora Nacional, 1969.

FERRANDo BADÍA, JUAN, coord. Estudio sobre el estatuto valenciano. El proceso autonómico. Valencia: Consell Valencià de Cultura, 1993

- Formas de Estado desde la perspectiva del Estado regional. Madrid: Instituto de Estudios Políticos, 1964.

FLOR, VICENT, coord. De país a comunitat. Valencianisme polític i regionalisme. Valencia: Afers, 2014.

Fuentes PrósPer, Víctor. “El curso académico 1975-1976 en la Universidad de Valencia y el movimiento de Profesores No Numerarios (P.N.N.s)". En El País Valenciano frente a la democracia, dirigido y coordinado por Juan Antonio Tomás Carpi. Valencia: PCPV, 1977, 2 vols.

GASCó Escudero, PATRICIA. La transición política en España: poder nacional y poder regional en UCD-Valencia, UCD-Castellón y UCD-Alicante (1976-1982). Valencia: Universidad de Valencia, tesis doctoral inédita, 2015. 
Guia I MARín, Joser. “Consell Democràtic del País Valencià (1975-1976)”, L'Espill, 65 (2021): 165-172.

HERnANDo SERRA, MARÍA PILAR. Una historia inacabada. El autonomismo valenciano de los años treinta. Valencia: Tirant lo Blanch, 2021.

LAFONT, RoBERT. La révolution régionaliste. Paris: Gallimard, 1967.

MARTí CASTELló, Josep. Socialistes d'un país imaginat. Una història del Partit Socialista del País Valencià (1974-1978). Valencia: Alfonso el Magnánimo, 2017.

MilLÁs, JAIME. Crónicas de la transición valenciana (1972-1985). Valencia: Alfonso el Magnánimo, 2015.

PAGÈS I BlANCH, PELAI, coord. La transició democràtica als Països Catalans, historia i memoria. Valencia: Universidad de Valencia, 2005.

Prats MAHIQUES, Lluís BERNAT. Democràcia cristiana i valencianisme. Història de la UDPV (1965-1978). Valencia: Alfonso el Magnánimo, 2019.

RAGIONERI, ERNESTO. Politica e amministrazione nella storia dell'Italia unita. Bari: Bari, 1967.

Rodríguez-FloRES, VEGA. Fer país. Comunismo valenciano y problema nacional (1970-1982). Valencia: Alfonso el Magnánimo, 2019.

- "Por un País Valenciano libre autónomo y socialista. El PSOE y la identidad valenciana (1974-1978)". Pasado y Memoria. Revista de Historia Contemporánea, 17 (2018): 103-125.

— coord. El 9 d'Octubre de 1977. El País Valencià quaranta anys després. Catarroja: Afers, 2017.

Rodríguez TejadA, Sergio. Zonas de libertad: dictadura franquista y movimiento estudiantil en la Universidad de Valencia. Valencia: Universidad de Valencia, 2009.

RotelLi, ETTORE. L'avvento della Regione in Italia. Dalla caduta del regime fascista alla Costituzione repubblicana (1943-1947). Milano: Giuffrè, 1967. - ed. Il regionalismo italiano. Antologia del pensiero regionalista dal Risorgimento ai nostri giorni. Milano: Comune di Milano,1962.

SANCHo LLUNA, JUAN LUIS. Los orígenes históricos del anticatalanismo de la transición valenciana (1976-1982). Tradición, resistencia y reacción. Valencia: Universidad de Valencia, tesis doctoral inédita, 2017.

SANZ, BENITO. Rojos y demócratas. La oposición al franquismo en la Universidad de Valencia. 1939-1975. Valencia: CCOO-PV, FEIS y Albatros, 2002.

SANZ, BENITO y FELIP, JoSEP MARIA. 1962-1982. La construcción política de la Comunidad Valenciana. Valencia: Alfonso el Magnánimo, 2006.

SAnZ, Benito y Romeu, Francesc, eds. Memoria histórica de la transición y la democracia valenciana. Valencia: Universidad de Valencia, 2006. 
SANZ, Jesús. La cara secreta de la política valenciana. De la predemocracia al estatuto de Benicàssim. Valencia: Fernando Torres, 1982.

VVAA. La Méditerranée de 1919 à 1939. Actes du Colloque organisé par le Centre de la Méditerranée moderne et contemporaine, 28-31 mars 1968. Paris: SEVPEN, 1969. 